\title{
LATE DEVELOPMENT OF MULTIPLE SUPERNUMERARY TEETH IN A PATIENT WITH HYPODONTIA
}

\author{
Tomasz Stefański', Lidia Postek-Stefańska², Maria Iwanecka-Zduńczyk \\ 'Department of Orthodontics, Medical University of Silesia, Katowice, Poland \\ ${ }^{2}$ Department of Pediatric Dentistry, Medical University of Silesia, Katowice, Poland \\ ${ }^{3}$ Orthodontic Clinic, Academic Centre for Dentistry, Bytom, Poland
}

\begin{abstract}
Hypo-hyperdontia is a very rare condition in which dental agenesis and supernumerary tooth (or teeth) occur concomitantly. The present case report describes late-forming multiple supernumerary teeth in all quadrants in a nonsyndromic boy with a radiographic diagnosis of mandibular incisor hypodontia made when the patient was 9 years of age. Developing supernumeraries were detected after uneventful orthodontic treatment using fixed appliances on a panoramic radiograph taken shortly after debonding at the age of 15 . Cone beam computed tomography was performed to determine the exact location of the extra teeth relative to normal dentition and identify possible root resorption. To the best knowledge of the authors, this is the first reported case of late-developing supernumeraries being a part of the hypo-hyperdontia condition. In conclusion, general dental practitioners should be aware of the rare possibility that a generally healthy individual may develop multiple supernumerary teeth even with the previous diagnosis of hypodontia.
\end{abstract}

KEY wORDs: hyperdontia, supernumerary teeth, hypodontia, hypo-hyperdontia.

J Stoma 2019; 72, 4: 190-192

DOI: https://doi.org/10.5114/jos.2019.91238

\section{INTRODUCTION}

The reported prevalence of supernumerary teeth in the permanent dentition ranges from $0.15 \%$ to $3.9 \%$ [8]. They are conveniently classified according to their location (mesiodens, paramolar, distomolar) or morphology (conical, tuberculate, supplemental, odontomes). The most common are maxillary midline supernumeraries. While single supernumerary tooth usually occur in isolation, multiple supernumerary teeth are typically associated with a congenital syndrome or a cleft palate. In non-syndromic patients, multiple supernumerary teeth usually have been found in the mandibular premolar area $[4,7,13]$.
Late-developing supernumeraries are those extra teeth that form after normal corresponding teeth of the same region have completed their root formation [7]. In a several reports of late-developing supernumerary teeth, they were mostly found in the mandibular premolar region $[2,5,6,9,11,14,17]$. Their prevalence in an orthodontic population has been reported to be $0.64 \%$ [10].

Hypo-hyperdontia is a very rare condition in which dental agenesis (excluding third permanent molars) and a supernumerary tooth or teeth occur concomitantly. The prevalence of non-syndromic hypo-hyperdontia ranges from $0.33 \%$ [15] to $0.73 \%$ [3] in the orthodontic population and could be below $0.1 \%$ when the general
JOURNAL OF STOMATOLOGY CZASOPISMO STOMATOLOGICZNE
AdDresS FOR CORRESPONDENCE: Dr. Tomasz Stefański, Academic Centre for Dentistry, 17 Academic Square, 41-902, Bytom, Poland, e-mail: tostef1@wp.pl

RECEIVED: 15.06.2019 • ACCEPTED: 06.08.2019 • PUBLISHED: 15.11.2019 
population is considered [1]. The condition was reported more commonly in males than in females with a $1.4: 1$ ratio $[8,16]$. Hypo-hyperdontia can affect either one or both jaws. To date, approximately 200 patients with hypohyperdontia have been reported in the English literature since $1932[1,8,16]$. In most of them, the anomaly was bimaxillary or involved only the anterior maxillary region $[8,16]$.

The aim of this report is to present for the first time a case of hypo-hyperdontia involving multiple late-developing supernumerary teeth and mandibular incisor hypodontia.

\section{CASE PRESENTATION}

A 9-year-old Caucasian boy was referred to the Clinic of Orthodontics at the Academic Centre for Dentistry in mixed dentition stage with a missing mandibular permanent central incisor and class I malocclusion. Extraoral examination and functional analysis showed no relevant alterations. Medical and dental history was noncontributory with no previous tooth extractions, facial trauma, premature birth, neonatal teeth, or numerical anomalies of the primary dentition. Family members had neither congenitally missing nor supernumerary teeth. The initial panoramic radiograph (Figure 1) confirmed the congenital absence of one mandibular incisor and showed normally developing other teeth, including third molars.

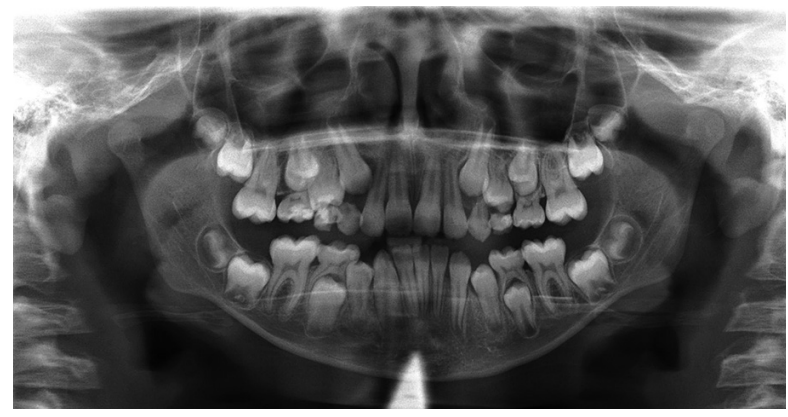

FIGURE 1. Panoramic radiograph taken during initial assessment at 9 years of age

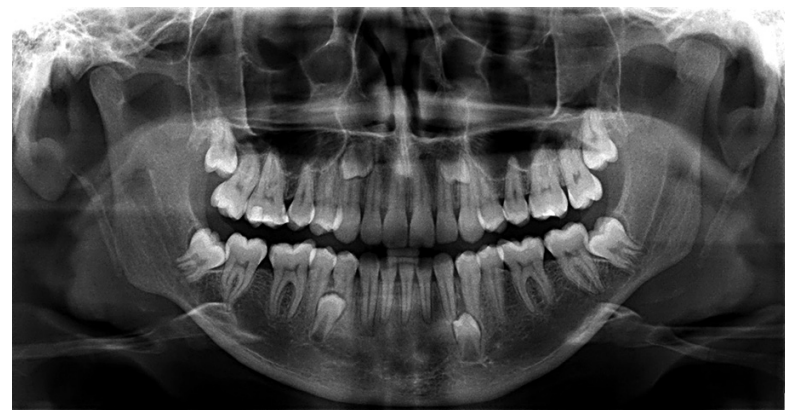

FIGURE 2. Panoramic radiograph after orthodontic treatment at 15 years of age
No radiographic evidence of other pathology was noted. Orthodontic treatment with fixed appliances commenced after the eruption of second molars and progressed uneventfully for 26 months. A second panoramic radiograph (Figure 2) was taken shortly after debonding at the age of 15 to assess the third molars and an unexpected finding was the presence of developing supernumerary teeth in all four quadrants. It was decided to perform cone beam computed tomography (CBCT) to determine the exact location of the supernumeraries relative to normal dentition and identify possible root resorption (Figure 3). The teeth were not associated with cyst formation or root resorption of adjacent teeth. Given the close proximity of the inferior alveolar nerve and the evidence that further extra teeth may be developing, the patient is being
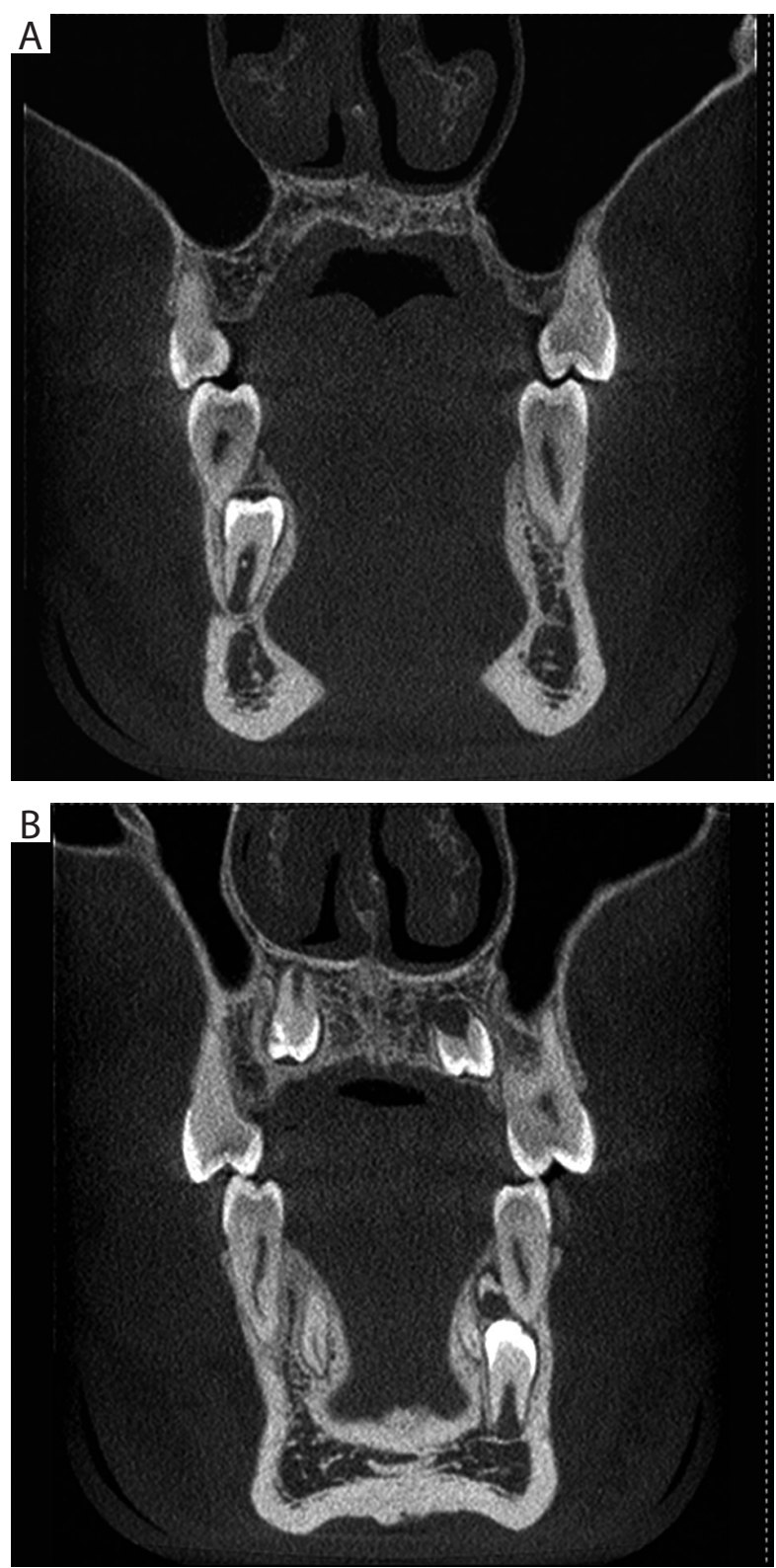

FIGURE 3. Cone beam computed tomography coronal scans at the level of supernumeraries 
monitored. Surgical intervention will be contemplated in the future.

\section{DISCUSSION}

Based on the published case reports it has been noted that patients with a previous history of supernumerary teeth in the anterior maxillary region have a greater possibility of developing supernumerary premolars at a later age [13]. They start calcifying around 10-15 years of age at the lingual site of the dental arch. They are thought to represent a part of the post-permanent dentition type of supernumerary tooth as they develop from an extension of the dental lamina after the permanent follicles have been formed and resemble normal premolar teeth [13].

Orthodontists may diagnose late-developing supernumerary teeth more often as panoramic radiographs are taken periodically during orthodontic treatment [7]. However, the supernumerary crypt and early stage of mineralization can be easily overlooked due to the lingual position relative to the normal premolar roots. Moreover, supernumerary premolars may interfere with orthodontic space closure and affect the stability of orthodontic treatment $[7,10,15]$.

Controversy exists regarding the timing for surgical removal of supernumerary premolars. To avoid the risk of damage to the roots and adjacent nerves some authors recommend leaving and monitoring them in situ until further development enables safer surgery. As the recurrence rate of supernumerary premolars has been reported to be $8 \%$ [13], the patient requires further regular and careful clinical and radiographic monitoring even after supernumerary premolars are surgically removed.

In the present case, late development of the supernumerary teeth was even more surprising as the patient had already been diagnosed with mandibular incisor hypodontia. To our best knowledge, this is the first report of multiple late-developing supernumerary teeth being a part of this unique numerical combination.

\section{CONCLUSIONS}

This is the only known documented case of late development of multiple supernumerary teeth in a patient with hypodontia. Dentists who treat children and young adolescents should take into consideration the rare possibility that a generally healthy individual despite the initial diagnosis of hypodontia is still capable of forming a supernumerary teeth.

\section{CONFLICT OF INTEREST}

The authors declare no potential conflicts of interest with respect to the research, authorship, and/or publication of this article.

\section{References}

1. Bowdin LM, Wong S, Anthonappa RP, King NM. Pre-maxillary hypohyperdontia: a report of two cases. Eur Arch Paediatr Dent 2018; 19: 117-123.

2. Chadwick SM, Kilpatrick NM. Late development of supernumerary teeth: a report of two cases. Int J Paediatr Dent 1993; 3: 205-210.

3. Gokkaya B, Kargul B. Prevalence of concomitant hypo-hyperdontia in a group of Turkish orthodontic patients. Eur Arch Paediatr Dent 2016; 17: 53-57.

4. Gunguz K, Avsever H, Orhan K, Canitezer G, Acikgoz A, Oz U, Midilli M. A multi-centre evaluation of multiple supernumerary premolar prevalence. Aust Orthod J 2015; 31: 149-156.

5. Hedge SV, Munshi AK. Late development of supernumerary teeth in the premolar region: a case report. Quint Int 1996; 27: 479-481.

6. Jamwal RS, Sharma P, Sharma R. Late-developing supernumerary mandibular premolar: a case report. World J Orthod 2010; 11: e94-98.

7. Khalaf K, Al Shehadat S, Murray CA. A review of supernumerary teeth in the premolar region. Int J Dent 2018; 2018: 6289047.

8. Mallineni SK, Nuvvula S, Cheung A, Kunduru R. A comprehensive review of the literature and data analysis on hypo-hyperdontia. J Oral Sci 2014; 56: 295-302.

9. Moore SR, Wilson DF, Kibble J. Sequential development of multiple supernmerary teeth in the mandibular premolar region - a radiographic case report. Int J Paediatr Dent 2002; 12: 143-145.

10. Paduano S, Rongo R, Lucchese A, Aiello D, Michelotti A, Grippaudo C. Late-developing supernumerary premolars: analysis of different therapeutic approaches. Case Rep Dent 2016; 2016: 2020489.

11. Pinchi V, Varvara G, Farese L, Norelli GA. Late development of a supernumerary premolar in a 17 -year-old female: timing of mineralization and medicolegal considerations. J Biol Regul Homeost Agent 2012; 26 (2 Suppl): 77-80.

12. Rubenstein LK, Lindauer SJ, Isaacson RJ, Germane N. Development of supernumerary premolars in an orthdontic population. Oral Surg Oral Med Oral Pathol Oral Radiol 1991; 71: 392-395.

13. Solares R, Romero MI. Supernumerary premolars: a literature review. Paediatr Dent 2004; 26: 450-458.

14. Suga SS, Kruly Pde C, Garrido TM, Matumoto MS, Suga US, Terada RS. Radiographic Follow-up during orthodontic treatment for early diagnosis of sequential supernumerary teeth. Case Rep Dent 2016; 2016: 3067106.

15. Varela M, Arrieta P, Ventureira C. Non-syndromic concomitant hypodontia and supernumerary teeth in an orthodontic population. Eur J Orthod 2009; 31: 632-637.

16. Wang YL, Pan HH, Chang HH, Huang GF. Concomitant hypohyperdontia: a rare entity. J Dent Sci 2018; 13: 60-67.

17. Yassaei S, Goldani Moghadam M, Tabatabaei SM. Late developing supernumerary premolars: reports of two cases. Case Rep Dent 2013; 2013: 969238. 